\title{
Downregulation of Forkhead Transcription Factor (FOXO3a) Contributes to Tumorigenesis of Acute Myeloid Leukemia and Chronic Myeloid Leukemia
}

\author{
Demet Akdeniz ODEMIS, Hulya YAZICI, Orkun GURBUZ, Seref Bugra TUNCER, \\ Ozge Sukruoglu ERDOGAN, Seda Kilic ERCIYAS, Betul CELIK, Mukaddes AVSAR, \\ Gozde Kuru TURKCAN, Nejat DALAY
}

Istanbul University, Oncology Institute, Department of Basic Oncology, Division of Cancer Genetics, Istanbul, TURKEY

\begin{abstract}
The expression of the $\mathrm{FOXO} 3 \mathrm{a}$ gene, and its role in acute myeloid leukemia and chronic myeloid leukemia were investigated in the present study. We analyzed 101 patients diagnosed with AML, and CML, and 34 healthy individuals. The cDNAs obtained from the blood samples of patients, and healthy controls were analyzed by the Real-Time PCR using specific primers, and probes for the FOXO3a and ACTB genes. A 50-fold decrease in FOXO3a expression levels was detected in CML patients, and 8-fold decrease was detected in AML patients compared with the levels in the healthy controls. Significant difference was detected between the patients, and healthy controls $(\mathrm{p}=0.000)$. However, there was no statistically significant difference between the $C M L$ and $A M L$ patient groups for FOXO3a expression level. The decrease in FOXO3a gene expression in all CML (51/51), and AML patients (50/50) was remarkable. The FOXO3a gene expression was downregulated in $91.8 \%$ (124/135) of all individuals included in the study. The present study might be an important report on emphasizing the expression profiles of FOXO3a gene in $\mathrm{AML}$, and $\mathrm{CML}$ patients. Whether the FOXO3a gene is a valuable biomarker for early diagnosis and prognosis in $C M L$ and $A M L$ patients need to be investigated in larger study groups.
\end{abstract}

Keywords: AML, CML, Leukemia, FOXO3a, Gene expression

\section{INTRODUCTION}

Leukemia is a malignant hematologic disease detected at any age group. Each year, 437.033 people are diagnosed with leukemia and $3.2 \%$ of the patients die of leukemia worldwide. ${ }^{1}$ Leukemias are divided into two groups as acute and chronic based on the percentage of blasts or leukemia cells in bone marrow or blood. Acute and chronic subgroups are also further divided into two subgroups and are named as myeloid or lymphoid based on the predominant lineage of the malignant cells. ${ }^{2}$ In general there are four major types of leukemia including acute myeloid leukemia (AML), chronic myeloid leukemia (CML), acute lymphoblastic leukemia (ALL), and chronic lymphocytic leuke- mia (CLL). ${ }^{3}$ Previous all epidemiologic and genetic studies demonstrated that leukemia has a multiple stage, and complex oncogenic process. Particularly the genetic and molecular changes which enable the malignant transformation of blood cells have significant contributions to the pathogenesis of leukemia, and disease heterogeneity. ${ }^{3}$ Therefore, understanding the genetic basis and molecular events of leukemia may provide new data on the diagnosis, prognosis, and treatment of leukemia. Forkhead box (FOX) proteins are the transcription factor protein family which are evolutionary protected. FOX proteins are the significant transcription factors which regulate the expressions of the genes associated with cell growth, cell proliferation, cell differentiation, and long life. ${ }^{4}$ 
FOX family is divided into various subfamilies such as FOXM, FOXK, FOXA, and FOXO families. ${ }^{5}$ Forkhead $\mathrm{O}$ transcription factors (FOXO) constitute one of the largest sub-groups of the forkhead family. FOXO family emerges as the common components of the pathways which regulate the various cellular functions including the inhibition of cell cycle, cell death, DNA repair, and stress stimulators, and which have critical roles in related physiologic and pathologic processes. FOXO family consists of four different members named as FOXO1, FOXO3a, FOXO4, and FOXO6 which are known to be regulated by the phosphoinositide 3-kinase (PI3K)-PKB signal pathway in mammals. FOXO family was shown to regulate the developmental processes, energy metabolism, and in addition to tumorigenesis in various tissues. The deregulation of FOXO functions results with carcinogenesis by causing uncontrolled cellular proliferation and accumulation of the DNA damage. A member of the FOXO sub-family, FOXO3a gene also known as FOXO3 is located on the 6q21 chromosome, and has important roles in the regulation of various cellular events such as apoptosis ${ }^{6}$, proliferation ${ }^{7}$, cell cycle progression ${ }^{8}$ and survival. ${ }^{9,10}$

The dysregulation of FOXO3a expression is known to be possibly associated with various diseases mainly cancer. ${ }^{10}$ The aberrant expression of FOXO has a significant role in development of leukemia. Deregulation of FOX proteins may change the cell fate by playing a key role in various cancers including leukemia. ${ }^{11}$ Therefore, FOX proteins constitute the potential targets for the diagnosis and treatment of various cancer. Conducted studies showed that FOXO proteins were associated with various biologic procedures such as in development, and progress of leukemia, and drug resistance after chemotherapy. ${ }^{3}$ Inhibition of FOXO function also by BCR-ABL1 transformation is a potentially important event even in hematological malignancies such as leukemias. ${ }^{12}$

The aim of the present study is to revea the complex regulatory mechanisms of FOXO3a gene in leukemia, and its critical role in leukemia pathogenesis. The role of FOXO3a gene in hematologic tumors such as AML, and CML was investigated in the scope of the study to highight the potential roles of FOXO3a in leukemia as therapeutic targets, and the prognostic indicators were discussed.

\section{MATERIALS AND METHODS}

\section{Study Design and Patient Characteristics}

The patients who presented to Istanbul University, Oncology Institute between 2010-2019 were selected. A study group of 135 individuals was created consisting of 51 patients diagnosed with CML, 50 patients diagnosed with AML, and 34 healthy individuals who were matched for age and sex with the patients. Particularly the untreated patients were recruited for the study. The individuals in the healthy control group were selected from the family with no history of cancer in their past 3 generations.

BCR-ABL1 fusion gene $\mathrm{t}(9 ; 22)$ translocation, and survival status of CML and AML patients were obtained from patient files registered in the Oncology Institute system of Istanbul University. BCR-ABL1 fusion gene was quantitatively evaluated using the Real-Time PCR method. The BCRABL1 fusion gene was quantitatively evaluated in routine practice of oncology using the Real-Time PCR method.

\section{Lymphocyte Separation from Whole Blood}

Lymphocyte separation was performed using the Ficoll (Sigma-Aldrich, Darmstadt, Germany) separation method. First, $10 \mathrm{~mL}$ Ficoll was included in a centrifuge tube, and the diluted blood was attentively poured into the Ficoll solution. After the tubes were centrifuged at $700 \mathrm{xg}$ for $30 \mathrm{~min}$ at room temperature, the white blood cells formed as circles were collected using a sterile pipette end without touching the Ficoll. Then, the white blood cells were diluted using $4 \mathrm{~mL}$ PBS, and placed in a cryotube. The precipitate was directly freezed and stored at $-80^{\circ} \mathrm{C}$ after the tubes were centrifuged at $700 \mathrm{~g}$ for 3-4 min at room temperature.

\section{RNA Extraction from Lymphocytes}

The blood cells were differentiated using the total RNA TRIzol reactive (ROCHE, Taufkirchen, Germany). First, the lymphocyte cells were homogenised in $1 \mathrm{~mL}$ TRIzol, and were left for incubation on ice for 5 minutes after including 200 $\mu \mathrm{L}$ chloroform. The mixture was centrifuged at $4^{0} \mathrm{C}$ for 15 minutes at $13.000 \mathrm{~g}$. The RNA phase 
was transferred to a new tube including $500 \mathrm{~mL}$ propanol. Then, the mixture was centrifuged at $4^{\circ} \mathrm{C}$ for 10 minutes at $13.000 \mathrm{~g}$. RNA involving pellet was washed using $75 \%$ alcohol, and dried at room temperature, and was dissolved in $30 \mu \mathrm{L}$ RNasefree water.

\section{cDNA Synthesis}

cDNA synthesis was performed from the RNAs obtained from the blood samples of the patients, and healthy controls using the RevertAid ${ }^{\mathrm{TM}}$ First Strand cDNA Synthesis Kit (Fermentas, Massachusetts, USA) protocol. First, $5 \mu \mathrm{L}$ RNA, $1 \mu \mathrm{L}$ random primer, and $6 \mu \mathrm{L}$ RNase-free water were mixed in a total of $12 \mu \mathrm{L}$ volume. The mixture was denaturated for 5 minutes at $65^{\circ} \mathrm{C}$, and placed on ice. After denaturation; $4 \mu \mathrm{L}$ reaction buffer, $1 \mu \mathrm{L}$ RNase inhibitor, $2 \mu \mathrm{L}$ dNTPs, and $1 \mu \mathrm{L}$ reverse transcriptase enzyme were added into the denaturated mixture, and placed on the PCR device. The reaction was ended after 5 minutes incubation at 70 ${ }^{\circ} \mathrm{C}$ following the incubation at $25^{\circ} \mathrm{C}$ for 5 minutes, and incubation at $42^{\circ} \mathrm{C}$ for 60 minutes.

\section{Quantitative Real-Time PCR}

The cDNAs obtained from patients, and from healthy controls were reproduced with real time PCR using special primer, and probes for FOXO3a, and ACTB genes. The target, and reference genes were together reproduced in the same reaction. The reaction conditions included a hot start of 10 minutes at $95^{\circ} \mathrm{C}$ and 45 cycles of amplification consisting of denaturation at $95^{\circ} \mathrm{C}$ for 30 seconds, annealing at $60^{\circ} \mathrm{C}$ for 30 seconds and extension at $72^{\circ} \mathrm{C}$ for 1 second. We used the FOXO3a / ACTB ratio for evaluating the relative expression level of FOXO3a in blood. At least two independent quantitative Real-Time PCR trials were performed for measuring the mean values for each specimen. The expression level of the FOXO3a gene of patients was compared with the expression in healthy controls.

The study was approved by the Local and Clinical Research Ethics Committee of Istanbul University (Ethical approval no: 2010/1104-373); according to the tenets of the Declaration of Helsinki (JAMA
1997; 277:925-926). The written informed consent was obtained from all participants or from the parents of children below 18 years of age. This work was supported by Scientific Research Projects Coordination Unit of Istanbul University (Project number: BAP-14286).

\section{Statistical Analysis}

The expression level of FOXO3a gene was determined by measuring the differences between the threshold cycles (CT). The target gene expression was normalized with the ACTB housekeeping gene expression, and calculated using the below formula of $2^{-\triangle \Delta \mathrm{CT}}$ equation.

$\Delta \mathrm{CT}=\mathrm{CT}_{\text {Fохоза }}-\mathrm{CT}_{\text {АСтB }}$, and $\Delta \triangle \mathrm{CT}=\mathrm{CT}_{\text {Patient }}-\mathrm{CT}_{\text {Healthy }}$

All tests were performed using the Statistical Package for the Social Sciences (SPSS) 21.0 program (SPSS, Chicago, IL, USA). The nonparametric tests were used during the analysis because the data showed no normal distribution. The changes in FOXO3a expression levels in patients, and healthy control groups were evaluated using the Kruskal Wallis, and Mann-Whitney U tests.

\section{RESULTS}

51 patients were diagnosed with CML, and 50 patients were diagnosed with AML. Control group consisted of 34 healthy individuals. The biologic features of all patients, and healthy control group are demonstrated in Table 1. The median age of CML patients at diagnosis was $50 \pm 2.21$ years(range 14-70 years); the median age of AML patients at diagnosis was $45 \pm 1.82$ years (range 1990 years); and the median age of control group was $50 \pm 2.85$ years (range $21-70$ years). $43.1 \%$ (22/51) of CML patients; $48 \%$ (24/50) of AML patients were diagnosed before 45 years; and also the age of $32.4 \%(11 / 34)$ of the control group was below 45 years. The female/male ratio in CML patients was 30/21; 26/24 in AML patients; and 21/13 in the healthy control group. BCR-ABL1 translocation rate was $96.1 \%$ for CML patients; and $2 \%$ for AML patients. There was a statistically difference between the expression level of the FOXO3a gene, and BCR-ABL1 translocation $(\mathrm{p}=0.000)$. The sur- 
International Journal of Hematology and Oncology

\begin{tabular}{|c|c|c|c|c|c|}
\hline & & $\begin{array}{l}\text { Low FOXO3a } \\
\text { Expression }\end{array}$ & $\begin{array}{l}\text { High FOXO3a } \\
\text { Expression }\end{array}$ & Total No (\%) & $\mathbf{p}$ \\
\hline \multirow[t]{16}{*}{ CML Patients } & \multicolumn{5}{|c|}{ Age (years) $50 \pm 2.21$ range $(14-70 \mathrm{y})$} \\
\hline & $<45$ years & $22(43.1 \%)$ & $0(0 \%)$ & $22(43.1 \%)$ & $p=0.955$ \\
\hline & $\geq 45$ years & 29 (56.9\%) & $0(0 \%)$ & 29 (56.9\%) & \\
\hline & Total & $51(100 \%)$ & $0(0 \%)$ & $51(100 \%)$ & \\
\hline & \multicolumn{5}{|l|}{ Sex } \\
\hline & Female & $30(58.8 \%)$ & $0(0 \%)$ & $30(58.8 \%)$ & $p=0.072$ \\
\hline & Male & $21(41.2 \%)$ & $0(0 \%)$ & $21(41.2 \%)$ & \\
\hline & Total & $51(100 \%)$ & $0(0 \%)$ & $51(100 \%)$ & \\
\hline & \multicolumn{5}{|c|}{ BCR-ABL1 t (9;22) } \\
\hline & Yes & $49(96.1 \%)$ & $0(0 \%)$ & $49(96.1 \%)$ & $p=0.000^{*}$ \\
\hline & No & $2(3.9 \%)$ & $0(0 \%)$ & $2(3.9 \%)$ & \\
\hline & Total & $51(100 \%)$ & $0(0 \%)$ & $51(100 \%)$ & \\
\hline & \multicolumn{5}{|l|}{ Survival } \\
\hline & Alive & $37(72.5 \%)$ & $0(0 \%)$ & $37(72.5 \%)$ & $p=0.000^{*}$ \\
\hline & Ex & $14(27.5 \%)$ & $0(0 \%)$ & $14(27.5 \%)$ & \\
\hline & Total & $51(100 \%)$ & $0(0 \%)$ & $51(100 \%)$ & \\
\hline \multirow[t]{16}{*}{ AML Patients } & \multicolumn{5}{|c|}{ Age (years) $45 \pm 1.82$ range (19-90 y) } \\
\hline & $<45$ years & $24(48 \%)$ & $0(0 \%)$ & $24(48 \%)$ & $p=0.187$ \\
\hline & $\geq 45$ years & $26(52 \%)$ & $0(0 \%)$ & $26(52 \%)$ & \\
\hline & Total & 50 (100\%) & $0(0 \%)$ & 50 (100\%) & \\
\hline & \multicolumn{5}{|l|}{ Sex } \\
\hline & Female & $26(52 \%)$ & $0(0 \%)$ & $26(52 \%)$ & $p=0.954$ \\
\hline & Male & $24(48 \%)$ & $0(0 \%)$ & $24(48 \%)$ & \\
\hline & Total & 50 (100\%) & $0(0 \%)$ & 50 (100\%) & \\
\hline & \multicolumn{5}{|c|}{ BCR-ABL1 t (9;22) } \\
\hline & Yes & $1(2 \%)$ & $0(0 \%)$ & $1(2 \%)$ & $p=0.000^{*}$ \\
\hline & No & 49 (98\%) & $0(0 \%)$ & 49 (98\%) & \\
\hline & Total & 50 (100\%) & $0(0 \%)$ & 50 (100\%) & \\
\hline & \multicolumn{5}{|l|}{ Survival } \\
\hline & Alive & 24 (48\%) & $0(0 \%)$ & $24(48 \%)$ & $p=0.000^{*}$ \\
\hline & Ex & $26(52 \%)$ & $0(0 \%)$ & $26(52 \%)$ & \\
\hline & Total & 50 (100\%) & $0(0 \%)$ & 50 (100\%) & \\
\hline \multirow[t]{8}{*}{ Controls } & \multicolumn{5}{|c|}{ Age (years) $50 \pm 2.85$ range $(21-70 \mathrm{y})$} \\
\hline & $<45$ years & $2(8.7 \%)$ & $9(81.8 \%)$ & $11(32.4 \%)$ & $p=0.000^{*}$ \\
\hline & $\geq 45$ years & $21(91.3 \%)$ & $2(18.2 \%)$ & $23(67.6 \%)$ & \\
\hline & Total & $23(67.6 \%)$ & $11(32.4 \%)$ & 34 (100\%) & \\
\hline & \multicolumn{5}{|l|}{ Sex } \\
\hline & Female & $11(47.8 \%)$ & $10(90.9 \%)$ & $21(61.8 \%)$ & $p=0.002^{*}$ \\
\hline & Male & $12(52.2 \%)$ & $1(9.1 \%)$ & $13(38.2 \%)$ & \\
\hline & Total & $51(67.6 \%)$ & $11(32.4 \%)$ & 34 (100\%) & \\
\hline
\end{tabular}

vival rate was $72.5 \%$ for CML patients; $48 \%$ for AML patients and there was a statistical difference between survival rate and FOXO3a gene expression $(\mathrm{p}=0.000)$.
The expression level of the FOXO3a gene of 101 patients measured, and analyzed using the Quantitative Real-Time PCR method was compared with the results of 34 healthy individuals. The 


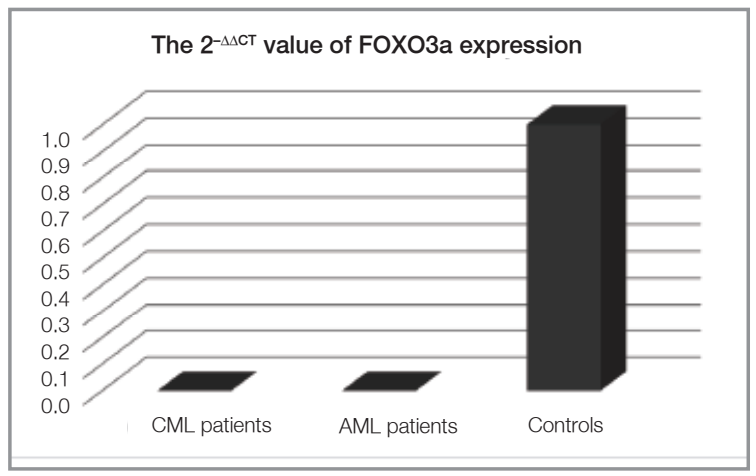

Figure 1. The $2^{-\triangle \triangle C T}$ value of $\mathrm{FOXO} 3 \mathrm{a}$ expression in patients with $C M L$ and $A M L$, and in the healthy controls

performed expression measurements showed that there was no statistically significant difference for FOXO3a gene expression between the CML, and AML patients. However, a statistically significant difference was detected in the comparison between both CML and AML patients and a healthy control group, separately. FOXO3a gene expression was shown to have decreased 50 folds in CML patients compared with the expression level in healthy control group and, also decreased 8 fold in AML patients compared with the expression levels in healthy control group. The measurements based on the mean values are presented in Table 2, and Figure 1.

The results of the statistical analysis using the SPSS showed that the expression level of FOXO3a was statistically significantly downregulated in CML patients, and in AML patients compared with the expression levels in healthy controls $(\mathrm{p}=0.000)$. The decrease in FOXO3a gene expression in all $(51 / 51 ; 50 / 50)$ CML, and AML patients was re-

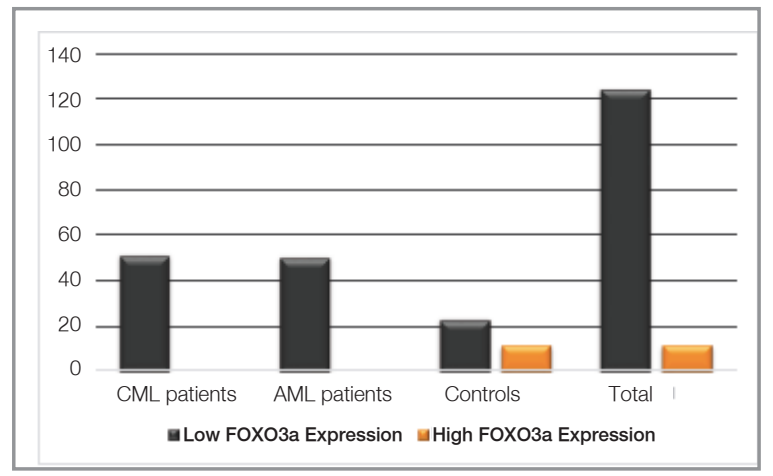

Figure 2. The low and high expression level of FOXO3a gene in patients with $\mathrm{CML}$ and $\mathrm{AML}$, and healthy controls

markable. Although the FOXO3a gene expression was downregulated in $67.6 \%$ (23/34), the FOXO3a gene expression was upregulated in $32.4 \%$ (11/34) in the control group. The FOXO3a gene expression was downregulated in $91.8 \%$ (124/135) of all individuals included in the study. The distribution of FOXO3a gene expression levels in the patients, and control group is demonstrated in Figure 2, and Table 3.

\section{DISCUSSION}

Leukemias are the heterogenous neoplastic disease group originating from the malignant transformation of the hematopoietic cells. Acute leukemia is a disease characterized with the infiltration of blood, bone marrow, and myeloid or lymphoid cells to the other tissues. CML is a clonal hematopoietic stem cell disease associated with the increased myeloid cells in all stages of differentiation. ${ }^{13}$ Presence of numerous genetic changes associated with AML,

\begin{tabular}{|c|c|c|c|c|c|}
\hline $\begin{array}{l}\text { The groups of } \\
\text { patients and } \\
\text { healthy controls }\end{array}$ & FOX03a $C_{T}$ & АСТВ $\mathrm{C}_{\mathrm{T}}$ & $\begin{array}{l}\Delta \mathrm{C}_{\mathrm{T}} \text { (Avg. FOXO3a } \\
\mathrm{C}_{\mathrm{T}} \text { - Avg. АСТВ } \mathrm{C}_{\mathrm{T}} \text { ) }\end{array}$ & $\begin{array}{l}\Delta \Delta \mathbf{C}_{\mathrm{T}} \text { ( Avg. } \Delta \mathbf{C}_{\mathrm{T}}- \\
\text { Avg. } \Delta \mathbf{C}_{\mathrm{T}} \text { healthy) }\end{array}$ & $\begin{array}{l}\text { Normalized } \\
\text { FOXO3a amount } \\
\text { relative to healthy } \\
2^{-\triangle \triangle C T}\end{array}$ \\
\hline CML patients & 31.43 & 18.57 & 12.85 & 5.49 & 0.02 \\
\hline AML patients & 29.20 & 18.92 & 10.28 & 2.92 & 0.13 \\
\hline Healthy Controls & 27.83 & 20.47 & 7.35 & 0 & 1 \\
\hline
\end{tabular}


International Journal of Hematology and Oncology

Table 3. Distribution of FOXO3a gene expression levels in CML and AML patients, and in the healthy control group

\begin{tabular}{|lllll|}
\hline & $\begin{array}{l}\text { FOXO3a } \\
\text { Low Expression } \mathbf{n}(\%)\end{array}$ & $\begin{array}{l}\text { FOXO3a } \\
\text { High Expression n (\%) }\end{array}$ & Total n (\%) & p \\
\hline CML patients & $51(41.1 \%)$ & $0(0 \%)$ & $51(37.8 \%)$ & $p=0.000^{\star}$ \\
AML patients & $50(40.4 \%)$ & $0(0 \%)$ & $50(37 \%)$ & $p=0.000^{\star}$ \\
Controls & $23(18.5 \%)$ & $11(100 \%)$ & $34(25.2 \%)$ & $p=0.000^{\star}$ \\
Total & $124(91.8 \%)$ & $11(8.2 \%)$ & $135(100 \%)$ & \\
\hline
\end{tabular}

and CML facilitated the performing of intensive studies on molecular mechanisms. Oncogene activation, and inactivation of the tumor suppressor genes are the mechanisms which were shown to be effective in both acute and chronic leukemia. ${ }^{14}$

FOXO transcription factors are located in the connection point of various significant signal pathways, and therefore they have critical roles in various physiologic and pathologic processes. The deterioration in FOXO function results with uncontrolled cell proliferation, and accumulation of DNA damage. ${ }^{3}$ FOXO transcription factors have roles in many biologic processes such as proliferation, survival, and escape of leukemic cells from apoptosis. ${ }^{15,16}$ The activation of FOXOs is also responsible from the formation of resistance mechanism in leukemia in addition to the cytotoxic reaction developing against anti-leukemia drugs. The FOXO3a enriched leukemia stem cells, and induced MDR genes contributed to the drug resistance in leukemia. ${ }^{3}$ The development of therapeutic agents which regain the functions of the tumor suppressor FOXOs may become a rational target for the treatment of leukemia. However, the double effects of FOXOs as a response to chemotherapy must be considered in developing the therapeutic agents targeting the FOXOs. In addition, FOXOs are the potential diagnostic and prognostic tools for leukemia in the clinic. FOXO proteins may represent the new therapeutic targets for a wider cancer spectrum.

The histopathologic research trying to associate the FOXO expression and localization with the disease occurrence in cancer patients showed that FOXOs have tumor suppressor role. Lower FOXO1 expression levels are associated with soft tissue sarcomas, AML, shorter disease free survival, and shorter overall survival in prostate, head-neck and breast cancer. ${ }^{17-21}$ Similarly, higher FOXO3a levels are associated with shorter disease free survival in clear cell renal carcinoma, colorectal, urothelial, neuroblastoma, and breast cancer. ${ }^{22-26}$ The FOX$\mathrm{O} 3 \mathrm{a}$ expression levels in patients with metastasis were found significantly lower compared with the primer tumor, and thus showed that the decrease in FOXO levels might be a significant prognostic indicator in the comparison of primer colorectal cancer patients, and patients with liver metastasis. ${ }^{22}$ However, one study performed particularly on AML patients showed that the increased expression of FOXO3a gene was associated with poor prognosis in AML patients which showed normal cytogenetic features. ${ }^{27}$ This was the evidence that FOXO3a gene have both tumor suppressor, and oncogenic features. We suggest that the cellular localization of the FOXO3a gene might be effective in the emergence of this mechanism. We found in our study investigating the FOXO3a gene expression level in CML, and AML patients that FOXO3a gene expression was statistically significantly decreased in all patients compared with the expression in the healthy control group. We also observed a dramatic decrease in all $101(100 \%)$ patients in our study group consisting of $51 \mathrm{CML}$, and 50 AML patients. Therefore, these results are the significant evidence that the downregulation of the forkhead transcription factor FOXO3a contributed to the tumorigenesis of this gene in CML, and AML.

The Philadelphia $(\mathrm{Ph})$ chromosome is formed by a reciprocal $\mathrm{t}(9 ; 22)$ (q34; q11) translocation between the long arms of chromosomes 9 and 22, resulting in fusion of the BCR and ABL1 genes. ${ }^{28}$ BCR-ABL1 protein, specifically structurally active tyrosine kinase activity that constitutes CML pathogenesis. Tyrosine kinase activation increases 
in the presence of $\mathrm{t}(9 ; 22)$ translocation, and today tyrosine kinase inhibitors (TKIs) are used as the treatment approach in CML patients. ${ }^{29}$ The presence of BCR-ABL1 can explain virtually all the cellular features of the leukaemia such as enhanced cell growth, inhibition of apoptosis, altered cell adhesion, growth factor independence, impaired genomic surveillance and differentiation. BCRABL1 promotes nuclear export and deactivation of FOXO transcription factors via PI3K/Akt. ${ }^{30}$ Measuring BCR-ABL1 transcript levels by quantitative PCR allows monitoring of initial treatment response and prediction of treatment failure and / or disease progression. ${ }^{31}$ As a result of our study, the comparison of FOXO3a expression levels of CML and AML patients in accordance with the BCRABL1 translocation status showed that $49 \mathrm{CML}$ patients had translocations and FOXO3a expression decreased dramatically in all these patients. This dramatic decrease in FOXO3a expression in CML patients with BCR-ABL1 translocation may lead to suppression of tyrosine kinase activity and consequently drug resistance to tyrosine kinase inhibitors administered to patients. $0.5-3 \%$ of all AML cases also carry BCR-ABL1 fusion gene. ${ }^{32}$ Therefore, TKIs are not recommended as the firstline treatment option for AML patients. In our study, BCR-ABL1 translocation was seen in only $2 \%$ of the AML patients and this rate is compatible with the literature. In addition, the survival rate of the patients wasfound as $72.5 \%$ in CML patients, and as $48 \%$ in AML patients. This survival rate in both CML and AML patients is also compatible with the literature. ${ }^{33-35}$

We suggest that this study might be an important report on emphasizing FOXO3a gene expression profiles in AML, and CML patients. Our study results suggested that the FOXO3a gene has a role in the oncogenesis of CML and AML and might be used as a therapeutic target in treatment of leukemia, and also could be a potential prognostic biomarker. Although the roles of FOXO proteins have not been defined in CML, and AML patients yet, further studies are required for a full understanding of the FOXO3a gene regulation mechanisms in leukemia cells.

\section{Acknowledgement:}

This work was supported by Scientific Research Projects Coordination Unit of Istanbul University (Project number: BAP-14286).

\section{REFERENCES}

1. Bray F, Ferlay J, Soerjomataram I, et al. Global cancer statistics 2018: GLOBOCAN estimates of incidence and mortality worldwide for 36 cancers in 185 countries. CA Cancer J Clin 68: 394-424, 2018.

2. Emadi A, Law JY. Overview of Leukemia. https://www.msdmanuals.com/professional/hematology-and-oncology/leukemias/overview-of-leukemia. Access date: November 21, 2020.

3. Zhu H. Targeting forkhead box transcription factors FOXM1 and FOXO in leukemia (Review). Oncol Rep 32: 1327-1334, 2014.

4. Carlsson P, Mahlapuu M. Forkhead transcription factors: key players in development and metabolism. Dev Biol 250: 1-23, 2002.

5. Hannenhalli S, Kaestner KH. The evolution of Fox genes and their role in development and disease. Nat Rev Genet 10: 233-240, 2009.

6. Chen YF, Pandey S, Day CH, et al. Synergistic effect of HIF1alpha and FoxO3a trigger cardiomyocyte apoptosis under hyperglycemic ischemia condition. J Cell Physiol 233: 36603671, 2018.

7. McClelland Descalzo DL, Satoorian TS, Walker LM, et al. Glucose-induced oxidative stress reduces proliferation in embryonic stem cells via FOXO3A/beta-catenin-dependent transcription of p21(cip1). Stem Cell Reports 7: 55-68, 2016.

8. McGowan SE, McCoy DM. Platelet-derived growth factor-A regulates lung fibroblast S-phase entry through p27 (kip1) and FoxO3a. Respir Res 14: 68-82, 2013.

9. Joseph J, Ametepe ES, Haribabu N, et al. Inhibition of ROS and upregulation of inflammatory cytokines by $\mathrm{FoxO} a$ promotes survival against Salmonella typhimurium. Nat Commun 7: 12748-12762, 2016.

10. Liu $Y$, Ao X, Ding W, et al. Critical role of FOXO3a in carcinogenesis. Mol Cancer 17: 104-116, 2018.

11. Kornblau SM, Singh N, Qu Y, et al. Highly phosphorylated FOXO3A is an adverse prognostic factor in acute myeloid leukemia. Clin Cancer Res 16: 1865-1874, 2010.

12. Ghaffari $S$, Jagani Z, Kitidis $C$, et al. Cytokines and BCR-ABL mediate suppression of TRAIL-induced apoptosis through inhibition of forkhead FOXO3a transcription factor. Proc Natl Acad Sci U S A 100: 6523-6528, 2003.

13. Childhood Acute Myeloid Leukemia/Other Myeloid Malignancies Treatment $(P D Q(R))$ : Health Professional Version. In: PDQ Cancer Information SummariesBethesda (MD), 2002. https://www.cancer.gov/types/leukemia/hp/child-aml-treatment-pdq. Access date: August 20, 2020. 
14. Hornsveld M, Dansen TB, Derksen PW, Burgering BMT. Reevaluating the role of FOXOs in cancer. Semin Cancer Biol 50: 90-100, 2018.

15. Tran H, Brunet A, Griffith EC, Greenberg ME. The many forks in FOXO's road. Sci STKE 172: RE5, 2003.

16. Accili D, Arden KC. FoxOs at the crossroads of cellular metabolism, differentiation, and transformation. Cell 117: 421426, 2004.

17. Zhang B, Tomita $Y$, Ch'ng E, et al. Prognostic significance of phosphorylated FOXO1 expression in soft tissue sarcoma. Ann Surg Oncol 16: 1925-1937, 2009.

18. Wu Y, Elshimali $Y$, Sarkissyan M, et al. Expression of FOXO1 is associated with GATA3 and Annexin-1 and predicts disease-free survival in breast cancer. Am J Cancer Res 2: 104 115, 2012.

19. Cheong JW, Eom JI, Maeng HY, et al. Constitutive phosphorylation of FKHR transcription factor as a prognostic variable in acute myeloid leukemia. Leuk Res 27: 1159-1162, 2003.

20. Zhang H, Pan $\mathrm{Y}$, Zheng L, et al. FOXO1 inhibits Runx2 transcriptional activity and prostate cancer cell migration and invasion. Cancer Res 71: 3257-3267, 2011.

21. Ekizoglu S, Dalay N, Karaman E, et al. LKB1 downregulation may be independent of promoter methylation or $\mathrm{FOXO} 3$ expression in head and neck cancer. Transl Res 162: 122-129, 2013.

22. Bullock MD, Bruce A, Sreekumar R, et al. FOXO3 expression during colorectal cancer progression: biomarker potential reflects a tumour suppressor role. Br J Cancer 2013 Jul 23. 109(2): 387-394, doi: 10.1038/bjc.2013.355.

23. Ni D, MaX, Li HZ, et al. Downregulation of FOXO3a promotes tumor metastasis and is associated with metastasis-free survival of patients with clear cell renal cell carcinoma. Clin Cancer Res 20: 1779-1790, 2014.

24. Smit L, Berns K, Spence K, et al. An integrated genomic approach identifies that the PI3K/AKT/FOXO pathway is involved in breast cancer tumor initiation. Oncotarget 7: 25962610,2016

25. Shiota M, Song Y, Yokomizo A, et al. Foxo3a suppression of urothelial cancer invasiveness through Twist1, Y-box-binding protein 1, and E-cadherin regulation. Clin Cancer Res 16: 5654-5663, 2010.

26. Santo EE, Stroeken P, Sluis PV, et al. FOXO3a is a major target of inactivation by PI3K/AKT signaling in aggressive neuroblastoma. Cancer Res 73: 2189-2198, 2013.

27. Santamaria CM, Chillon MC, Garcia-Sanz R, et al. High FOXO3a expression is associated with a poorer prognosis in AML with normal cytogenetics. Leuk Res 33: 1706-1709, 2009.

28. Score J, Calasanz MJ, Ottman O, et al. Analysis of genomic breakpoints in p190 and p210 BCR-ABL indicate distinct mechanisms of formation. Leukemia 24: 1742-1750, 2010.

29. Druker BJ, Guilhot F, O'Brien SG, et al. Five-year follow-up of patients receiving imatinib for chronic myeloid leukemia. $N$ Engl J Med 355: 2408-2417, 2006.

30. Atfi A, Abecassis L, Bourgeade MF. Bcr-Abl activates the AKT/Fox O3 signalling pathway to restrict transforming growth factor-beta-mediated cytostatic signals. EMBO Rep 6: 985-991, 2005

31. Chereda B, Melo JV. Natural course and biology of CML. Ann Hematol 94: Suppl 2: S107-121, 2015

32. Neuendorff NR, Burmeister T, Dorken B, Westermann J. BCR-ABL-positive acute myeloid leukemia: a new entity? Analysis of clinical and molecular features. Ann Hematol 95: 1211-1221, 2016

33. Cancer Facts \& Figures 2020. https://www.cancer.org/content/dam/cancer-org/research/cancer-facts-and-statistics/ annual-cancer-facts-and-figures/2020/cancer-facts-andfigures-2020.pdf. Access date: November 21, 2020.

34. Survival Rates for Chronic Myeloid Leukemia. https://www. cancer.org/cancer/chronic-myeloid-leukemia/detection-diagnosis-staging/survival-rates.html. American Cancer Society. Access date: June 19, 2018.

35. Nall R. Survival Rates and Outlook for Acute Myeloid Leukemia (AML). https://www.healthline.com/health/acute-myeloid-leukemia-survival-rates-outlook. Access date: February 3, 2020

\section{Correspondence: \\ Dr. Demet Akdeniz ODEMIS}

Istanbul Universitesi, Onkoloji Enstitutusu

Temel Onkoloji Anabilim Dali,

Kanser Genetigi Bilim Dali Arastirma Laboratuari

Millet Caddesi, Topkapi Mahallesi

34093 Fatih, ISTANBUL / TURKEY

Tel: (+90-543) 5136324

e-mail: akdenizdemet@gmail.com

\section{ORCIDs:}

Demet Akdeniz Odemis

Hulya Yazici

Orkun Gurbuz

Bugra Seref Tuncer

Ozge Sukruoglu Erdogan

Seda Kilic Erciyas

Betul Celik

Mukaddes Avsar

Gozde Kuru Turkcan

Nejat Dalay
0000-0002-2271-8481 0000-0002-8919-0482 0000-0001-7488-4361 0000-0001-8023-3223 0000-0002-0893-1251 0000-0003-4417-4005 0000-0001-7923-275X 0000-0002-5489-9088 0000-0001-5974-4731 0000-0003-1479-3577 